\title{
Method of quantitative assessment of the regularities of natural restoration of biota in zones of technogenic disturbance by extractive enterprises
}

\author{
Jury Galchenko ${ }^{1 *}$ and Julia Ozaryan ${ }^{2}$ \\ ${ }^{1}$ Institute of Comprehensive Exploitation of Mineral Resources Russian Academy of Sciences, \\ Moscow, Russia \\ ${ }^{2}$ Mining Institute of Far eastern branch of Russian Academy of Sciences, Khabarovsk, Russia
}

\begin{abstract}
The paper presents the results of field studies of tendencies in plant communities self-regeneration processes in the zone of their technogenic disturbance and on the surfaces of rock spoil heaps. It has been established that in the former case the key factor determining the nature of development of self-regeneration processes is the correspondence of the width of the transitional community to the length of transfer of seeds of primary plant community edificatory and assectator species. In the latter case, the key self-regeneration succession sere passes the bifurcation point at a very early stage of its development.
\end{abstract}

\section{Introduction}

The contemporary stage of development of the conflict between humans and the Earth's natural biota is characterised with gradual "greening" of mentality. Both the harmfulness of uncontrolled development of the technocratic civilisation and total futility of biocentrism under the slogan "back to nature" have been acknowledged. The growing contradictions between intellect and nature generated by many centuries-long dominance of the ideology of unlimited human consumption of natural resources inevitably lead to rapid degradation of the Earth's natural biota to the extent of its total destruction. The obvious danger of such processes made this problem a top priority of further development of the entire human civilisation.

The growing understanding of the fact that environmental protection and conservation in the current technocratic civilisation development model is a fight against consequences rather than the root causes of the problem calls for an urgent need for radical revision of the principles of interaction between the technological and biological spheres.

In respect of exploration of mineral resources, especially new mineral deposits situated on territories still unaffected by human impact, the problem of development of principles of design, construction and operation of utility infrastructure facilities of extractive enterprises acquires a no lesser (and perhaps even greater) importance, as it enables to maintain within

*Corresponding author: schtrek33@mail.ru 
the biota tolerance boundaries all forms of anthropogenic burden caused by compact human habitation.

At the same time, for mining enterprises whose period of existence is limited by the exhaustibility of its commercial resources, the specifics of regeneration succession in the post-operational period are of particular interest. The research of regeneration of arboreal species in different parts of the territory under survey in the post-operational period provides a general picture of the tendencies in this process.

It is necessary to address two types of tasks:

- development of demutation processes in the zone of technogenic degradation of primary ecosystems of the natural biota;

- development of natural regeneration succession on the surfaces of technologyinduced neoformations (primarily rock spoil heaps).

\section{Methodology and objects of research}

The new approaches were built on principles of sustainable development, which are interpreted in our country as the strategy of sustainable development of the environment and society [1]. The research of plant communities self-regeneration processes was conducted in the zone of technogenic disturbance adjoining the industrial site of an underground mine with the annual capacity of over 1 million tonnes of ore, shut down more than 25 years ago [1]. As well as in a quarry for the extraction of building materials, where there are piles of overburden, where the restoration of vegetation occurs from five to fifty years [2]. The modern phytocoenotic landscapes surveillance methodology consisted in route survey of a mountain river basin and description of phytoecological profiles underlying the valley and adjacent slopes. Geobotanical pictures of the forest association were made and the undergrowth of arboreal species was measured at $2 \times 50 \mathrm{~m}$ discount plots. The distances between profiles varied from $2.5 \mathrm{~km}$ to $4 \mathrm{~km}$. Secondary profiles were underlying the valleys of some tributary streams [3-5].

\section{Results and discussion}

According to the findings of this research, the channel pebbled beach and the second bottom of the valley were planted by Populus maximovichzii, Henri, Chosenia macrolepis, Turaz, Fraxinus mandshurica, Rupr, Aser mono, Rupr, Acer mandshuricum Maxim, Suringa amurensis, Rupr, Alnus hirsuta, Turcz, and some other arboreal species. Judging by the nature of regeneration of different species, the natural succession process in this standard natural zone is characterised with an increasing role of Fraxinus mandshurica, Rupr, Acer mandshuricum Maxim, and Aser mono, Rupr, which are gradually superceding Populus maximovichzii, Henri, and Chosenia macrolepis, Turaz, in the edificator synusia.

The integrated effect of anthropogenic objects on the entire territory of the rest of the valley resulted in the formation of a totally different (as compared to the initial) vegetation complex. The forest cover on both slopes of the valley contained only two associations (or types) of planted vegetation deriving from the initial woodland:

- In the bottom section of the slope, it is multi-species deciduous forest consisting of Betula mandshurica Na Kai, Betula costata, Trautv, Populus tremula, L., Tilia amurensis, Kom, Aser mono, Rupr, and Acer mandshuricum Maxim, with insignificant additions of species of the initial forest stand. Abies holophulla, Maxim., is represented by single overmatured trees and rare groups of tall undergrowth. There are also single species of overmatured Pinus koraiensis, Sieb. et Zucc, with pronounced top drying. 
- The top section and the ridge are also covered by Kalopānax septemlōbus, Micromeles alnifolia and Betula schmidtii. This means that the initial three-storeyed mixed coniferous-deciduous forest has transformed into a polydominant community of smallleaved deciduous species.

The structure of undergrowth on most of its area fully corresponds to the known specifics of degradation-and-demunation successions caused by disturbances of initial coniferous- deciduous forest stand. Aser mono, Rupr (5,000 species/hectare), Acer mandshuricum Maxim (6,000 species/hectare), Acer pseudosieboldianum, Kom. (3,500 species/hectare), and Tilia amurensis, Kom. (2,800 species/hectare) regenerate better than other species. Pyrogenic species - Betula mandshurica Na Kai, and Populus tremula, L. hardly regenerate at all. There is practically no coniferous understory of young regeneration either and little hope for its emergence in the future. All this is an indication that after technological and anthropogenic burdens are lifted further succession will most probably be developing towards the formation of multi-species forest stand on this territory with the prevalence of broadleaved species. In other words, the changes in initial biota caused by durable operation of an extractive enterprise have largely acquired an irreversible nature.

The process of regeneration of arboreal species in the zone of transitional community between second-growth forest and part of initial forest remaining in areas with difficult access is totally different. Owing to technological causes of its formation, the border between mature forest stand of these two communities is rather well pronounced and a zone of transition of properties for this part of the plant community is practically non-existent. However, it is quite visible in the case of undergrowth of the main forest forming species. All the remaining primary biota areas in this ecosystem are surrounded by a strip (ecotone) which, in addition to the regenerated second-growth forest community species, also has occasional species of the standard forest-forming community (fig. 1). The intensity of this process for all these species declines as the distance from the mother plants increases depending on the seeds transfer mechanisms. The identified trends in changes of the undergrowth density and its species composition on territories of second-growth forest communities adjacent to the remaining areas of primary plant communities show that the distance of transfer of seeds of the main forest-forming species can be used as one of the criteria of regulation of the sizes of singular land allotments during the formation of infrastructure of an extractive enterprise's surface complex.

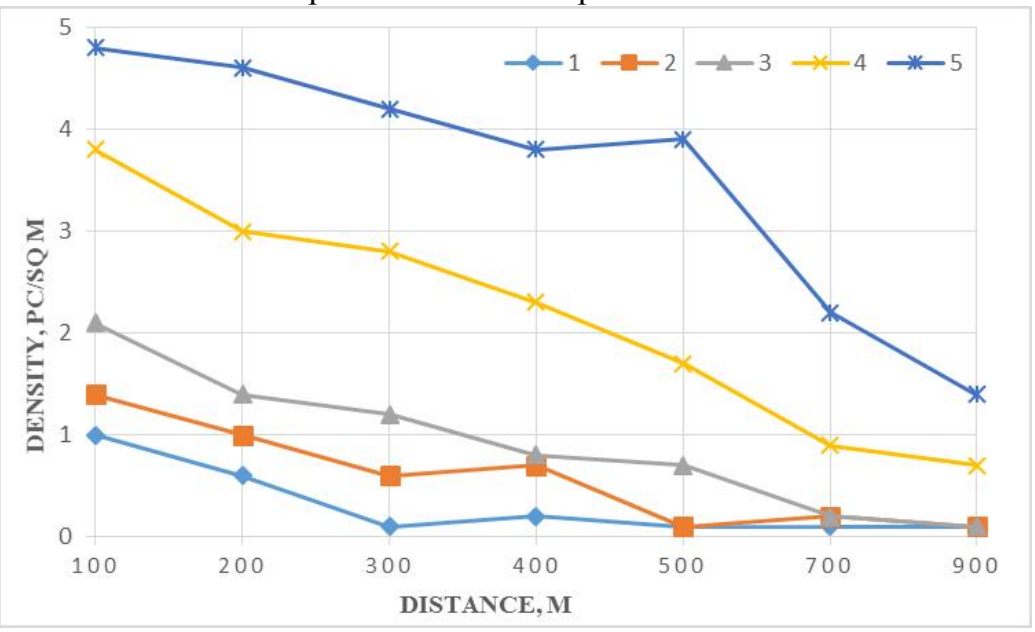

Fig. 1. Dynamics of the main forest-forming species undergrowth density within the zone of the ecotone between the standard and second-growth forest communities ( 1- Pinus koraiensis, Sieb. et Zucc; 2 -Jurglans manshuriga Maxim.; 3 - Abies holophulla, Maxim.; 4 - Acer; 5 - Betula costata, Trautv.) 
The Korfovsky Rock Querry is situated on the borderline of the Bolshoy Khekhtsyr State Nature Reserve, in connection with which the flora and fauna of the adjacent territories are quite diverse. It has a wide representation of various types of deciduous, mixed coniferous-deciduous, and dark coniferous forests. The species composition of the region numbers over 1000 vascular plants.

As the territory of the mineral block allocation used to be covered with forest vegetation, it is obvious that it must be regenerated through environmental measures. This calls for a need to explore the processes of self-regeneration of the territories disturbed in the process of solid waste accumulation of mining production. In addition, the examination of processes of natural regeneration of disturbed lands is important for establishing the levels of tolerance and assessment of resilience of organisms and their self-regeneration potential.

The soils of rock spoil heaps are generally potentially fertile. Moreover, longer periods of overburden rock storage in the spoil heaps lead to improvement of physical and mechanical characteristics and structure of the soils.

It should be mentioned that 1-2 years after the formation of a spoil heap its surface becomes covered with pioneer grassland vegetation represented by 2-3 species, most frequently Artemísia vulgáris and Trifolium hybridium L. [6]

The research of demutation processes was conducted at rock spoil heaps during the survey of their vegetative cover (figure 2, tab.1).

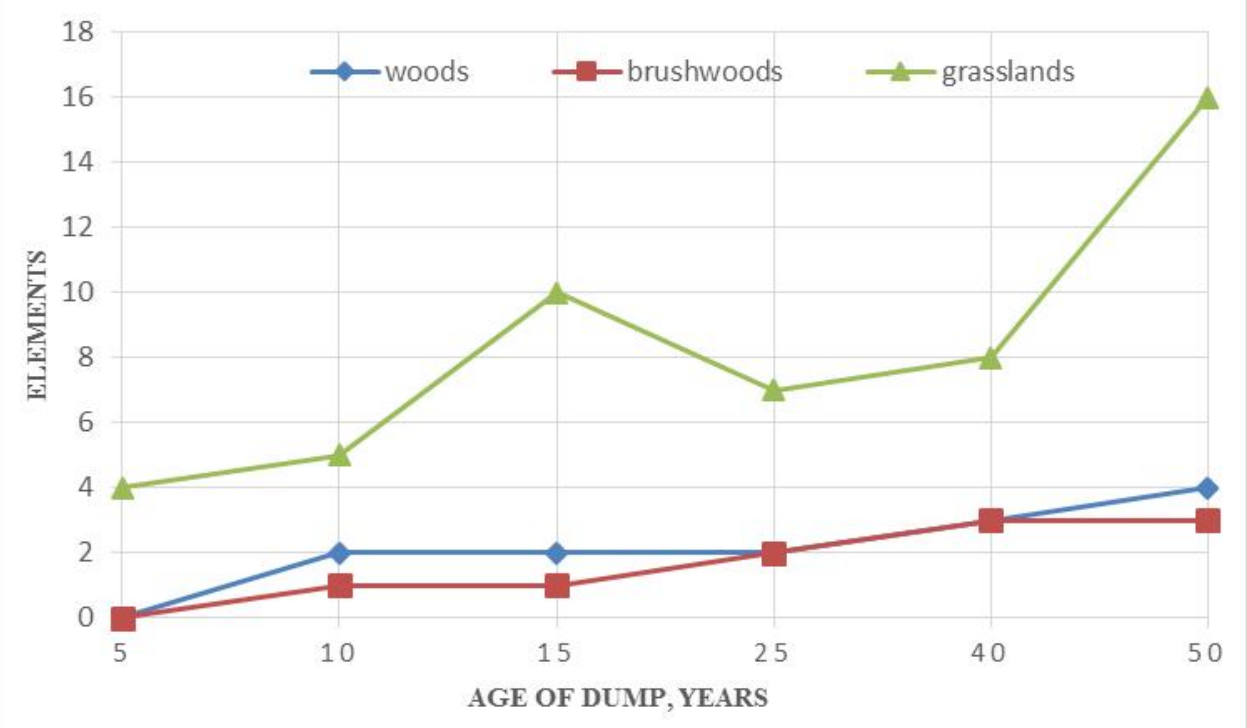

Fig. 2. Change in the number of species over time

The pioneer vegetation of rock spoil heaps is represented by herbs of the following families: legumes: Trifolium hybridium L., Melilotus albus Medik; gramineous species: Alopecurus pratensis, Gramineae, Poa praténsis; sunflower family: Artemísia vulgáris, Tanacetum L., Taraxácum officinále, Crepis tectorum L., and others. Arboreal plants involved in demutation processes include Salix schwerinii, Salix sachalinensis 'Sekka,' Populus maximovichzii, Henri, Betula albosinensis, and Duschekia fruticosa, Betulaceae.

In the first five years regeneration of vegetation is insignificant: occasionally Artemísia vulgáris, Alopecurus pratensis, Gramineae, Trifolium hybridium L., Taraxácum officinále. The plants are not tall, up to $5 \mathrm{~cm}$ high, and their number does not exceed 18 species per 1 square metre. Arboreal plants can be found occasionally at rock spoil heaps 
(10 years and more) adjacent to the forest edge: Betula albosinensis, Salix schwerinii, Populus maximovichzii, Henri.

In the ten subsequent years the species composition of the herb stratum is quite varied and is represented by the following species: Oenothera suaveolens, Trifolium lupinaster, Crepis tectorum L., Artemísia vulgáris, Artemísia scopária, Taraxácum officinále, Plantágo média, Pulsatílla pátens, Chamerion angustifolium, and Trifolium hybridium L. Trifolium hybridium L. is known to have a favourable effect on the quality of soils as it improves the nitrogen balance stimulating the accumulation of organic matter and formation of the humus layer. In the later period some species fall out, but new ones appear.

Table 1. Structure of natural regeneration plant community

\begin{tabular}{|c|c|c|c|}
\hline \multirow{2}{*}{$\begin{array}{c}\text { Areas of self-regeneration } \\
\text { (rock spoil heaps, age, years) }\end{array}$} & \multicolumn{3}{|c|}{ Number of species } \\
\cline { 2 - 4 } & \multicolumn{3}{|c|}{ including } \\
\cline { 2 - 4 } & woods & brushwoods & grasslands \\
\hline 5 & 0 & 0 & 100 \\
\hline 10 & 25 & 12.5 & 62.5 \\
\hline 15 & 15.38 & 7.69 & 76.92 \\
\hline 25 & 18 & 18 & 63 \\
\hline 40 & 21.43 & 21.43 & 57.14 \\
\hline 50 & 17.39 & 13.04 & 69.56 \\
\hline $\begin{array}{c}\text { Background } \\
\text { (natural vegetation) }\end{array}$ & 34.78 & 15.22 & 49.99 \\
\hline
\end{tabular}

The demutation process is dominated by Salix schwerinii and Populus maximovichzii, Henri, and among herbous plants - by Artemísia vulgáris, Taraxácum officinále, and Trifolium hybridium L.

The variety of herbal species on the ground of the background territory numbers 46 species, which is exactly twice as high as the number of species on the 50-year-old spoil heap. 16 arboreal species, 7 shrub vegetation species, and 23 grass vegetation species have been found here. It should be mentioned that the soil and vegetation cover is more diverse here, and most species are not found in the enterprise impact zone.

Such characteristics of self-organised vegetation processes can be explained by low content of humus in the substance and its unfavourable physical and mechanical features. The soils consist mainly of rocky and sandy mixtures, as a result of which moisture cannot be retained in the substance, and this leads to the absence of the water regime necessary for vegetation.

Key plant communities have been identified on the basis of the conducted analysis, and the key succession seres of the plant community self-regeneration at rock spoil heaps of the Korfovsky Rock Querry was produced (figure 3). The produced succession sere provides a graphic picture of the processes of replacement of some communities with others which is useful for subsequent analysis of the findings.

The first stage of demutation processes is the basis of a succession sere - it includes leguminous forbs and gramineous forbs communities. It has been established that the grass community dominated by leguminous species is being superseded by shrubs with the prevalence of Alnus hirsuta, Turcz., and in the event of presence of gramineous species the 
dominant species is Salix schwerinii. In addition, in the former case shrubs are superseded by young birch forest, and in the former case - by mixed wood and shrub community.

Apparently, there is no regular pattern in the changing stages of the succession sere. The appearance of some or other species in the plant community depends on the nature of transfer of seeds taking place in a particular season of the year, otherwise it requires other specific conditions of the natural environment. Nevertheless, special mention should be made of total absence of natural regeneration of coniferous species, which indicates that the regeneration succession process under these conditions has passed the point of bifurcation at a very early stage of its development [7].

It is known that depending on their length successions are classified into local, secular, and phylocoenogenetic (evolution of plant associations) successions. All these types of successions are closely connected with each other and overlap. The supersession of coniferous-deciduous forest by mixed deciduous forest is an example of local succession characteristic of the territory under survey. Regeneration of the primary forest plant community will proceed within a different timescale as a result of secular succession.

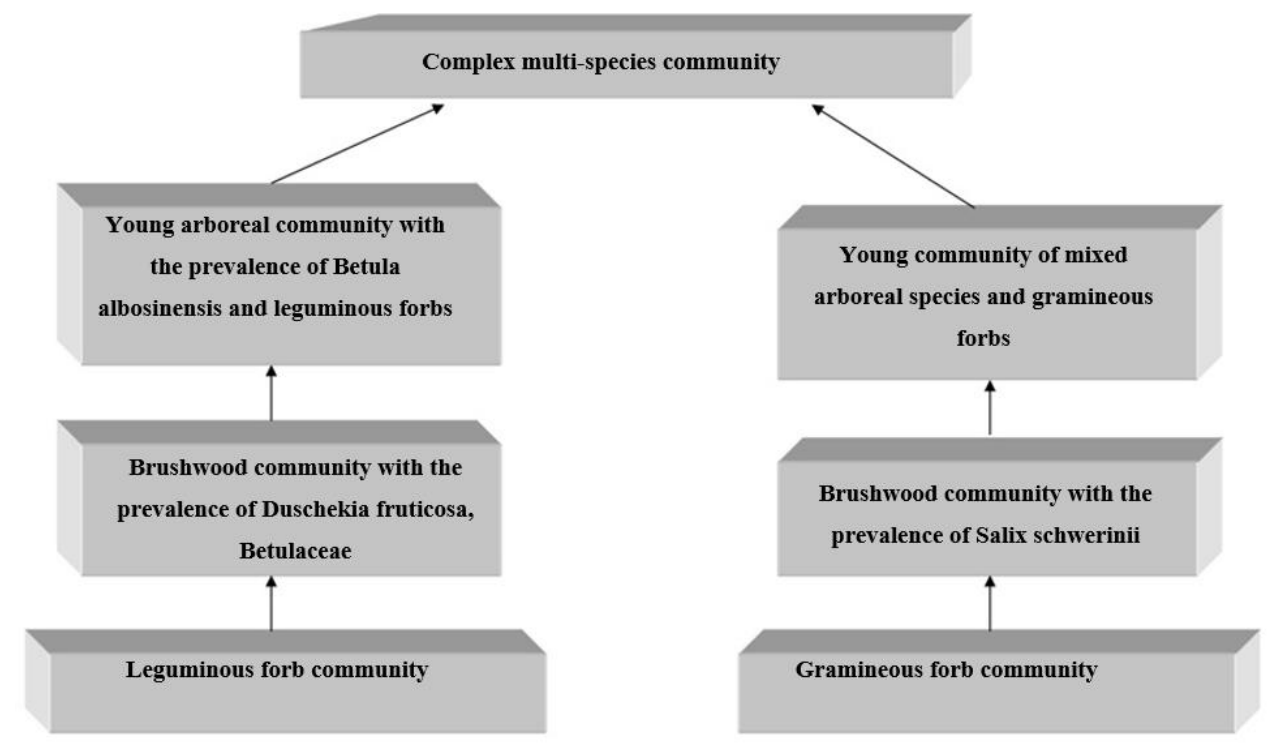

Fig. 3. Succession seres of the plant community self-regeneration at rock spoil heaps

\section{Conclusions:}

The dominant development of the mineral and raw materials complex prioritises the problem of localising inevitable disturbances of the biota in time and space by creating conditions for development of regenerative successions of plant communities.

The area of technology-induced disturbance of the natural biota caused by operation of an extractive enterprise is considerably larger than the area of the enterprise's land allotment.

The methodology of rehabilitation of territories disturbed by mining works must be based on initiation of processes of natural self-regeneration of plant communities.

The intensity and tendency of demutation processes in the zone of technogenic disturbance of the biota depend on the presence of a source and mechanisms of transfer of seeds of the edificatory group of the plant community. 
A complex multi-species community regenerates through development of a key succession sere, but because of bifurcation of the process natural regeneration of the initial biota does not happen at the local succession level.

\section{References}

1. K.N. Trubetskoi, Yu.P. Galchenko, L.I Burtsev. Environmental Problems of Exploitation of Mineral Resources under Sustainable Development of the Environment and Society. Moscow: Nauchtekhlitisdat. p. 262 (in Russian). (2003).

2. K.N. Trubetskoi, Yu.P. Galchenko Geoecology of the development of the Earth's interior and ecogeotechnology for the development of deposits Moscow: Nauchtekhlitisdat. p. 360 (in Russian). (2015).

3. Yu.A.Monakov, A.N. Kupriyanov Kuzbass-1: Sat. articles. GIAB. Fascicle 7. (2009).

4. A.V. Bogorodskaya, O.V. Trefilova, A.S. Shishikin. Bulletin of Tomsk State University. 382. P. 214-220. (2014).

5. $\quad$ Klaas G.J.N., van Lagen B., Buurman P. Geoderma. 100. P. 1-24. (2001).

6. Yu.P. Galchenko, M.B. Bubnov, Yu.A. Ozaryan. Environmental Systems and Tools. 7. pp. 25-32 (in Russian). (2013).

$7 . \quad$ V.V. Furyaev. Role of Fires in the Process of Forest Formation. Novosibirsk: Nauka. RAS Siberian Publishing Firm. p. 253 (in Russian). (1996). 